\title{
Viscoelasticity and texture of spreadable cheeses with different fat contents at refrigeration and room temperatures
}

\author{
S. Bayarri, I. Carbonell, and E. Costell ${ }^{1}$ \\ Instituto de Agroquímica y Tecnología de Alimentos, CSIC, Avenida Agustín Escardino 7, 46980, Paterna, Valencia, Spain
}

\begin{abstract}
The effect of the 2 common consumption temperatures, refrigeration temperature $\left(10^{\circ} \mathrm{C}\right)$ and room temperature $\left(22^{\circ} \mathrm{C}\right)$, on the viscoelasticity, mechanical properties, and perceived texture of commercial cream cheeses was studied. Two samples with different fat contents, regular and low fat, from each of 4 selected commercial brands were analyzed. The selection criteria were based on identification of brands with different percentages of fat content reduction between the regular- and low-fat samples (35, 50, 84, and 98.5\%). The fat content of regular-fat samples ranged from 19.8 to $26.0 \%$ (wt/wt), and that of low-fat samples ranged from 0.3 to $13.0 \%$ (wt/wt). Viscoelasticity was measured in a controlled-stress rheometer using parallel-plate geometry, and the mechanical characteristics of samples were measured using the spreadability test. Differences in the intensity of thickness, creaminess, and roughness between the regular- and low-fat samples of each commercial brand were evaluated at each of the selected temperatures by using the paired comparisons test. At $10^{\circ} \mathrm{C}$, all samples showed higher viscoelastic modulus values, firmness, and stickiness, and lower spreadability than when they were measured at $22^{\circ} \mathrm{C}$. Differences in viscoelasticity and mechanical properties between each pair of samples of the same brand were greater at $10^{\circ} \mathrm{C}$ than at $22^{\circ} \mathrm{C}$ because of the influence not only of fat content but also of fat state. Ingestion temperature did not modify the sensory differences detected between each pair of samples in terms of creaminess and roughness, but it did modify the differences detected in thickness. The joint consideration of sample composition, fat state, and product behavior during oral processing could explain the differences detected in thickness perceived because of measurement temperatures.
\end{abstract}

Key words: spreadable cheese, fat content, temperature, texture

Received May 10, 2012.

Accepted July 6, 2012.

${ }^{1}$ Corresponding author: ecostell@iata.csic.es

\section{INTRODUCTION}

Mechanical and rheological properties of cheeses are the predominant stimuli affecting in-mouth texture perception during mastication and swallowing. However, other textural characteristics, especially those related to surface and structural features (creaminess, smoothness, or fattiness) can play a definitive role in the perceived texture of different types of cheeses (Foegeding and Drake, 2007; van Vliet et al., 2009). Cream cheese or spreadable cheeses have a very different texture from hard and semisoft cheeses. During oral processing, they do not fracture, but some structural breakdown occurs as a result of work between the tongue and hard palate, mouth temperature, and product contact with saliva (de Wijk et al., 2011). Furthermore, although textural characteristics perceived in the mouth are the most important stimuli in cream cheese texture evaluation, a nonoral textural characteristic, spreadability, is also an important cream cheese attribute for consumers (Swenson et al., 2000; Glibowski at al., 2008). Spreadability is perceived by both the eyes and the hand, and can be defined as the pressure required to achieve a uniform distribution over a surface (Daubert at al., 1998).

Spreadable cheese texture is influenced by some processing conditions, such as temperature, agitation, homogenization pressure, and cooling rate (Swenson et al., 2000; Piska and Štětina, 2004); basic composition, which is mainly moisture, fat content, and protein content (Lee at al., 2004; Dimitreli and Thomareis, 2008); and the addition of emulsifying salts (Weiserovà et al., 2011) or different thickeners, such as starch (Trivedi et al., 2008) or pectin (Liu et al., 2008). All these variables can influence the product structure to a different extent and also modify its rheological, mechanical, and sensory properties. Among them, fat content is one of the most important. It is well known that variation in fat content alters the original balance among fat, protein, carbohydrates, and moisture, often giving rise to perceptible changes in texture (Banks, 2007). The mouth textural attributes and also resistance to spreading are closely related to fat content (Breidinger and Steffe, 2001; Brighenti et al., 2008). Muir et al. (1997) observed that fat content clearly influences the 
sensory dimensions associated with the texture and mouthfeel of commercial spreadable cheeses. Likewise, Wendin et al. (2000) showed that to describe sensory differences among samples with different fat content, texture attributes were more important than taste and flavor attributes. Bayarri et al. (2012) reached a similar conclusion in a previous work, when they compared the sensory profiles of commercial spreadable cheeses differing in fat content. They observed that variation in fat content affects texture attribute intensity more than do odor and flavor attributes.

Most of the information about the viscoelasticity (Lee et al., 2004; Piska and Štětina, 2004; Dimitreli and Thomareis, 2008), mechanical characteristics (Swenson et al., 2000; Liu et al., 2008), and perceived texture (Wendin et al., 2000; Bayarri et al., 2012) of cream cheeses has been obtained at only one temperature, mainly refrigeration temperature (from 5 to $8^{\circ} \mathrm{C}$ ) or at room temperature (from 18 to $22^{\circ} \mathrm{C}$ ), and different effects of fat content variation were observed in cheese characteristics. Some authors compared the effect of both temperatures (refrigeration temperature and room temperature) on the viscoelasticity and spreadability of this type of product (Breidinger and Steffe, 2001; Glibowski et al., 2008; Kulkurnainet al., 2008). In general, as the temperature decreased, the viscoelastic modulus values increased and spreadability decreased. Gliguem et al. (2009) studied the thermal and rheological properties of high-fat spreadable cheeses at different cooling rates, from 60 to $3^{\circ} \mathrm{C}$. They detected a relationship between the viscoelastic properties of cheese and the crystallization and melting properties of fat, and concluded that fat crystallization was responsible for the rapid increase in viscoelastic modulus values that occurred when the temperature decreased from 13 to $3^{\circ} \mathrm{C}$. Brighenti et al. (2008) characterized the viscoelastic behavior of commercial cream cheese samples with differing fat content during a heating-and-cooling cycle (5$\left.80-5^{\circ} \mathrm{C}\right)$. They observed that in full-fat cheeses, during heating between 5 and $40^{\circ} \mathrm{C}$, melting of the fat caused a decrease in the storage modulus $\left(\mathbf{G}^{\prime}\right)$ value and an increase in the loss tangent $(\tan \delta$ ) value. These authors also showed that fat-free cheeses exhibited different viscoelastic properties during the heating-and-cooling cycle compared with full-fat cheeses. These results suggest that temperature changes influenced the rheological and mechanical characteristics of spreadable cheeses with differing fat content to a different extent. From a practical point of view, it is important to know how the 2 most common consumption temperatures influence viscoelasticity and mechanical characteristics, including spreadability. Another important question is whether differences in ingestion temperature could influence the perceived texture of cream cheeses. Engelen et al.
(2003) pointed out the interest in knowing the influence of common serving temperatures on the sensory perception of foods. They compared the effect of 2 common serving temperatures $\left(10\right.$ and $\left.22^{\circ} \mathrm{C}\right)$ on the perception of texture attributes of low-fat $(0.2 \%$ fat $)$ and high-fat (4.3\% fat) commercial custard desserts and concluded that product temperature influenced the perception of certain textural attributes. To date, no information has been published on how product temperature influences the perceived texture of spreadable cheeses.

The aims of this study were (1) to compare the effect of the 2 common consumption temperatures, refrigeration temperature (approximately $10^{\circ} \mathrm{C}$ ) and room temperature (approximately $22^{\circ} \mathrm{C}$ ), on viscoelasticity, mechanical properties (including spreadability), and the perceived texture of commercial cream cheeses with differing fat content, and (2) to investigate whether, despite the influence of processing conditions and other ingredients, fat content of the sample is related to physical and sensory changes attributable to the temperature variation considered.

\section{MATERIALS AND METHODS}

\section{Samples}

Eight samples of commercial spreadable cheeses of 4 different brands (A, B, C, and D) were purchased from local supermarkets. Two samples with differing fat content, regular and low fat, were purchased from each brand, taking into account the sell-by dates. The selection criteria were based on a previous analysis of the commercial product range and on identification of brands with different percentages of fat content reduction between regular- and low-fat samples: A, 35\%; B, $50 \%$; C, $84 \%$; and D, $98.5 \%$. The fat content of regularfat samples ranged from 19.8 to $26.0 \%$ (wt/wt), and that for low-fat samples ranged from 0.3 (practically a fat-free sample) to $13.0 \%$ (wt/wt; Table 1). All samples were stored at $4 \pm 1^{\circ} \mathrm{C}$ before testing. All measurements were performed within the declared shelf-life period of each sample. Sample $\mathrm{pH}$ was measured in duplicate for each sample at room temperature with a Crison GLP 21 digital pH meter (Crison Instruments $\mathrm{SA}$, Barcelona, Spain). The $\mathrm{pH}$ values ranged from 4.52 to 5.03 for low-fat sample D and regular-fat sample A, respectively (Table 1 ).

\section{Rheological Measurements}

Viscoelasticity was measured in an RS1controlledstress rheometer (Haake, Karlsruhe, Germany) using parallel-plate geometry (60 mm diameter; 1-mm gap). Measurements were taken at 2 temperatures: $10 \pm 1$ 
Table 1. Identification of samples, nutritional facts, ${ }^{1}$ and $\mathrm{pH}$ of commercial spreadable cheeses

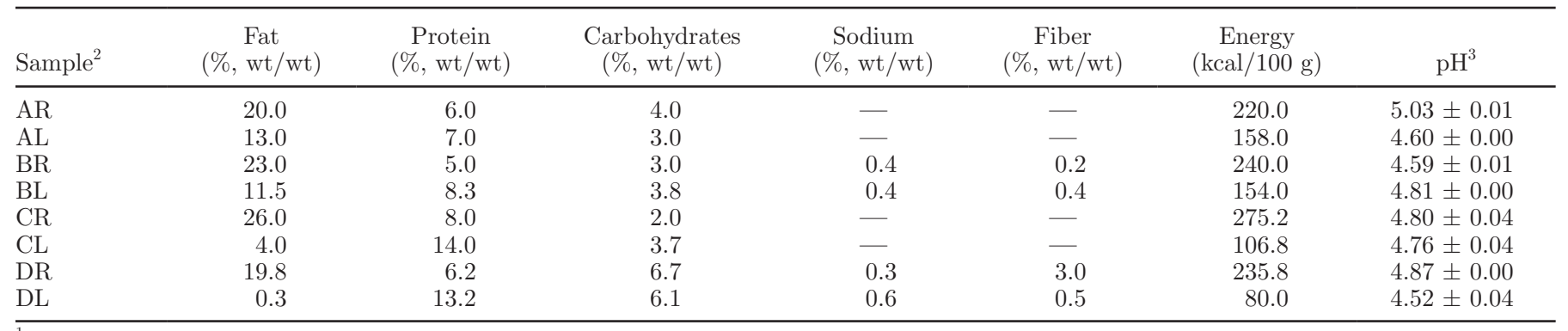

${ }^{1}$ As listed on the label.

${ }^{2} \mathrm{~A}, \mathrm{~B}, \mathrm{C}, \mathrm{D}=$ samples of different commercial brands; $\mathrm{R}=$ regular-fat samples; $\mathrm{L}=$ low-fat samples.

${ }^{3}$ Mean values of 2 replications $\pm \mathrm{SD}$.

and $22 \pm 1^{\circ} \mathrm{C}$, selected as representative of the common consumption temperatures of spreadable cheeses. The sample temperature during measurements was controlled by means of a Phoenix P1 Circulator device (Thermo Haake, Karlsruhe, Germany) circulating water bath. At least 2 packs of each sample were measured twice at each temperature. Before being tested, samples were carefully placed in the measuring system, and the excess material was wiped off with a spatula and allowed to rest for $10 \mathrm{~min}$ for structure recovery and temperature equilibration. A fresh sample was loaded for each measurement.

Stress sweeps were made between 2.00 and 2,000 $\mathrm{Pa}$, at a frequency of $1 \mathrm{~Hz}$, at the 2 temperatures (10 and $22^{\circ} \mathrm{C}$ ) to determine the linear viscoelasticity zones. Other information was also obtained from this experiment by observing the $\mathrm{G}^{\prime}$ and loss modulus $\left(\mathbf{G}^{\prime \prime}\right)$ variation when stress increased. First, the $G^{\prime}$ and $G^{\prime \prime}$ values remained relatively constant until a particular stress value was reached. At this stress value, the $G^{\prime}$ and $G^{\prime \prime}$ values decreased following different trends. The applied stress, at which the curves of $\mathrm{G}^{\prime}$ and $\mathrm{G}^{\prime \prime}$ intersect, was considered the critical stress value (Rao, 2007; Bayarri et al., 2009). Frequency sweeps at $10 \mathrm{~Pa}$, which is within the linear viscoelastic regions for all samples at both temperatures $\left(10\right.$ and $22^{\circ} \mathrm{C}$ ), were then performed from 0.01 to $10 \mathrm{~Hz}$, and the values of $\mathrm{G}^{\prime}, \mathrm{G}^{\prime \prime}$, $\tan \delta$, and complex viscosity $\left(\boldsymbol{\eta}^{*}\right)$ were registered as a function of frequency by using Rheowin Job software (v. 2.93, Haake). To study how differences in temperature influenced the viscoelastic properties of the samples with differing fat content, $\mathrm{G}^{\prime}, \mathrm{G}^{\prime \prime}, \eta^{*}$, and $\tan \delta$ values at $1 \mathrm{~Hz}$ were compared. This frequency was selected because it was considered a reasonable compromise between measuring at a very fast frequency, at which entanglements could contribute to solid-like responses, and measuring at extremely low frequencies, at which loss of precision and measurement reliability could be a problem (Clark and Ross-Murphy, 1987). When measuring the visco- elastic behavior of semisolid products, several authors have obtained a good correlation between the perceived thickness and the complex dynamic viscosity value at $50 \mathrm{rad} / \mathrm{s}$ (Bayarri et al., 2011). In this work, values of $\eta^{*}$ at $8 \mathrm{~Hz}\left(\boldsymbol{\eta}_{8 \mathrm{~Hz}}\right.$; equivalent to $\left.50 \mathrm{rad} / \mathrm{s}\right)$ were also calculated, with this value considered a possible index of oral thickness.

\section{Mechanical Measurement}

The mechanical characteristics of samples were measured using the spreadability test. The test was performed using a TA.XT2 Texture Analyzer equipped with a Texture Technologies Corporation (TTC, Scarsdale. NY) spreadability fixture (Stable Micro System, Ltd., Goldaming, UK) and a 30-kg load cell. As in the rheological tests, measurements were performed at 2 temperatures, $10 \pm 1$ and $22 \pm 1^{\circ} \mathrm{C}$. At least 2 packs of each sample were measured twice at each temperature, with a fresh sample used for each measurement. The TTC spreadability fixture is a set of precisely matched male and female Perspex $45^{\circ}$ cones. Cheese samples were placed inside the female cone, which was then pressed down with minimal structural disruption to eliminate air pockets. Any excess sample was removed with a spatula to leave a flat test surface. Samples were equilibrated and tempered at each of the specified temperatures $\left(10\right.$ or $\left.22^{\circ} \mathrm{C}\right)$ before testing. Once the test had commenced, the male cone penetrated the cheese sample at $1.0 \mathrm{~mm} / \mathrm{s}$ and continued to a depth of $2 \mathrm{~mm}$. During this last stage, the product was squeezed out from between the cones. Finally, the male cone was withdrawn from the sample. Force-time curves were recorded (Figure 1), with the force $(\mathrm{N})$ at the maximum penetration depth (F1) being taken as sample firmness. The area under the positive curve $(\mathrm{N} / \mathrm{s} ; \mathrm{A} 1)$ represented the total amount of force required to perform the shearing process, and it has been considered a good instrumental measurement of spreadability in 


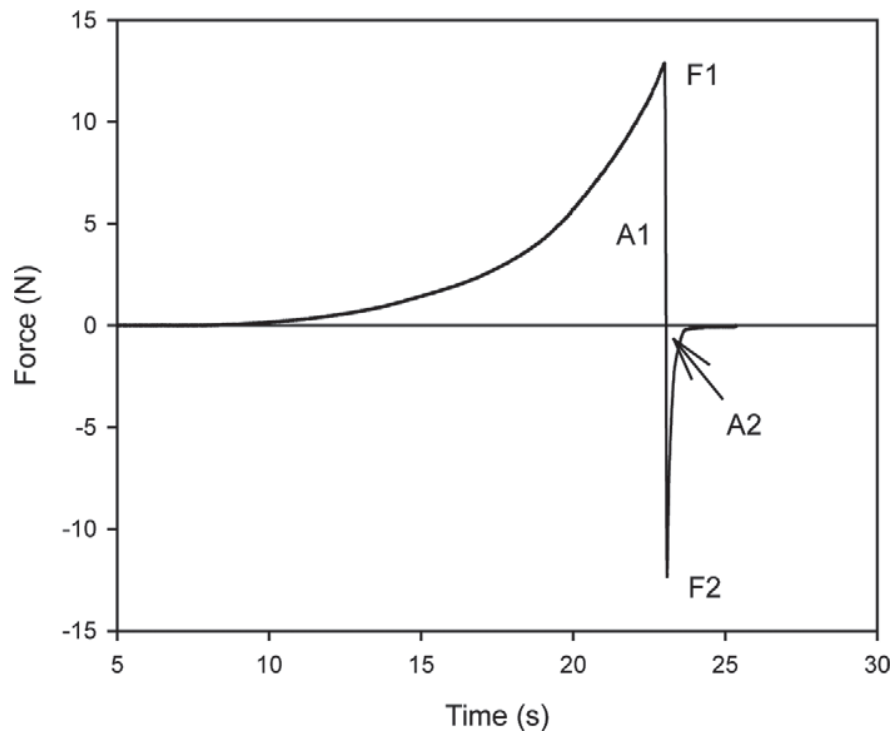

Figure 1. A typical force-time spreadability test curve. A1 = spreadability; F1 = firmness; F2 = stickiness; A2 = adhesiveness.

cream cheeses and in other spreadable products $(\mathrm{Sw}-$ enson et al., 2000; Canet et al., 2005; Glibowski et al., 2008; Brighenti et al., 2008). Smaller values in this area indicate easier spreadability. The force $(\mathrm{N})$ of the maximum negative peak indicates sample stickiness, and the maximum negative area $(\mathrm{N} / \mathrm{s} ; \mathrm{A} 2)$ represents the work of adhesion.

\section{Sensory Analysis}

Differences in the intensity of thickness, creaminess, and roughness between the regular- and low-fat samples of each commercial brand were evaluated at each of the selected temperatures $\left(10\right.$ and $\left.22^{\circ} \mathrm{C}\right)$ by using the paired comparisons test (ISO, 2005). The study was carried out by a group of 42 assessors with previous experience in sensory analysis of dairy products and were selected according to their capacity to detect differences in the intensities of the above-cited attributes (ISO, 1993). Each assessor evaluated 4 pairs of samples per session over 2 sessions. To reduce the possible effect of the serving order, for each pair of samples an equal number of assessors received a different sample first. Samples (10 to $12 \mathrm{~g}$ ) were presented in white plastic cups coded with 3-digit random numbers. Mineral water was provided for mouth rinsing. All sessions were carried out in the morning (1100 to $1200 \mathrm{~h}$ ) in separate booths, in a standardized test room (ISO, 2007). Data acquisition and data analysis were performed using Compusense five software, release 5.0 (Compusense Inc., Guelph, ON, Canada).

\section{Statistical Analysis}

Rheological and Mechanical Data Analysis. Two-way ANOVA with the interaction, considering sample and temperature as factors, was applied to each rheological and mechanical characteristic. Significant differences between individual samples were determined by Fisher's test $(P=0.05)$. Principal components analysis was applied to the average values of viscoelastic parameters. All calculations were carried out with XLSTAT-Pro software, v.2007 (Adinsoft, Paris, France).

Sensory Data Analysis. Sensory data were processed using Compusense five software, release 5.0 (Compusense Inc.). Tests were considered one tailed, and significant differences were established for $P=$ 0.05 .

\section{RESULTS AND DISCUSSION}

\section{Viscoelastic Behavior}

Stress sweeps showed differences among samples in the linear viscoelastic range (i.e., the interval of applied stresses where the structure of the samples remained unaffected). Differences were also observed between the dynamic modulus values in the linear viscoelastic region of samples tested. For all 4 brands, the stress dependence of $\mathrm{G}^{\prime}$ and $\mathrm{G}^{\prime \prime}$ was lower for the regular-fat sample. For both the regular- and reduced-fat samples of each brand, the linear viscoelastic range increased when the temperature decreased from 22 to $10^{\circ} \mathrm{C}$. For example, stress sweeps obtained at both temperatures (22 and $10^{\circ} \mathrm{C}$ ) for regular- and low-fat samples for 2 of the commercial brands (A and D) are shown in Figures 2 and 3. Samples of these commercial brands corresponded to the lowest and highest percentages of fat reduction, 35 and $98.5 \%$, respectively (Table 1). The effects of temperature variation on the linear viscosity range and on $G^{\prime}$ and $G^{\prime \prime}$ values in this region were higher for the samples with a regular-fat content (Figures $2 \mathrm{a}$ and $3 \mathrm{a}$ ) than for samples with a reduced-fat content (Figures $2 \mathrm{~b}$ and $3 \mathrm{~b}$ ). Differences observed between the dynamic modulus values in the linear viscoelastic region between samples attributable to both fat content and temperature were reflected by differences in critical stress values. In this work, critical stress values could not be obtained for 2 of the regular-fat samples (A and B) when measurements were taken at $10^{\circ} \mathrm{C}$. For these samples the $G^{\prime}$ and $G^{\prime \prime}$ crossover point was higher than 2,000 $\mathrm{Pa}$ and was out of the stress value range applied in this work (Figure 3a). Critical stress values were higher for samples with regular-fat content, indicating that higher stress was needed to destroy their internal structure. 

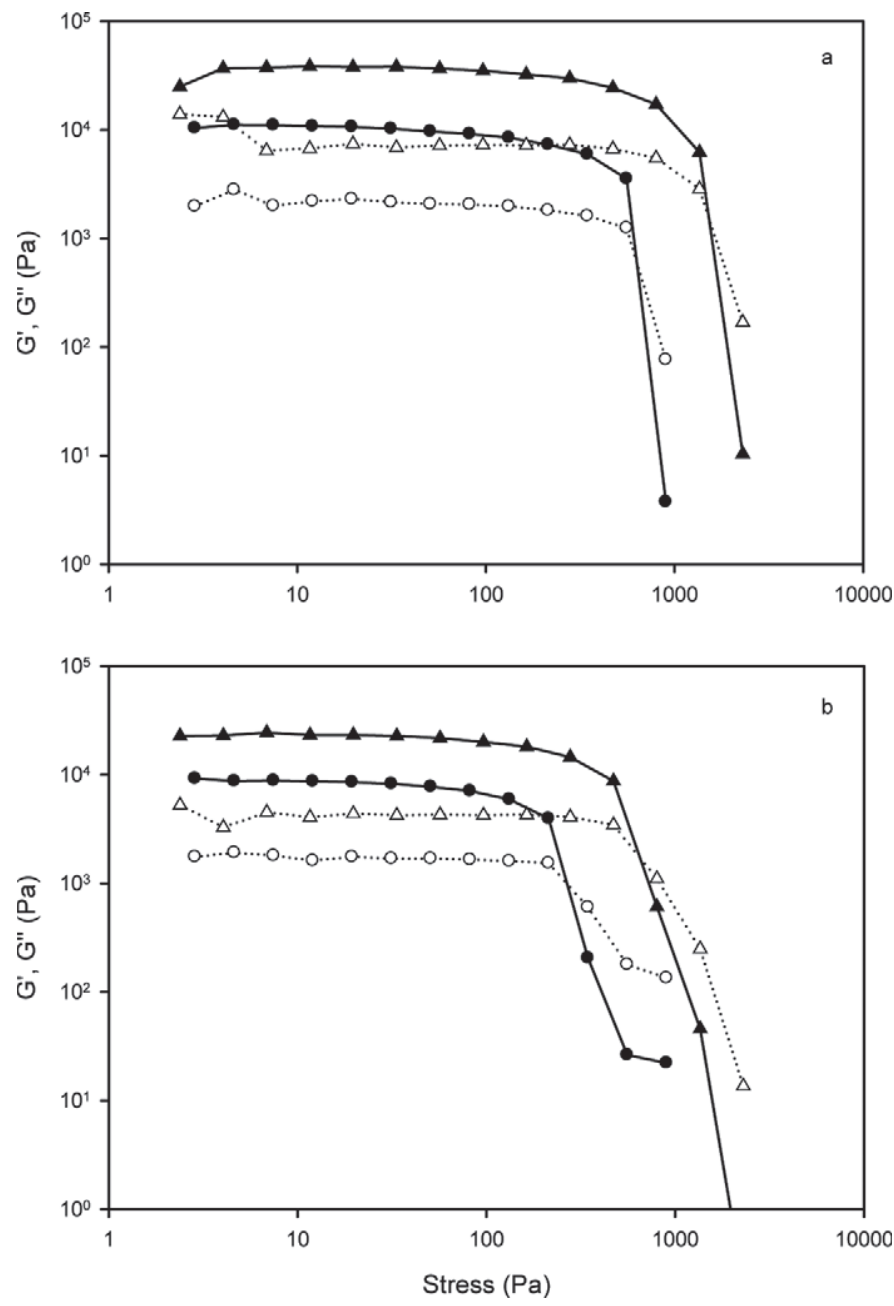

Figure 2. Stress sweeps of commercial spreadable cheeses of brand A: a) regular fat (20\% fat) and b) low fat (13\% fat) at different temperatures (circles, $22^{\circ} \mathrm{C}$; triangles, $\left.10^{\circ} \mathrm{C}\right)$. Storage modulus $\left(\mathrm{G}^{\prime}\right.$; filled symbols) and loss modulus ( $\mathrm{G}^{\prime \prime}$; empty symbols).

As expected, when the temperature decreased, critical stress values increased and the observed variation was higher for regular-fat samples (Figure 4).

According to the stress sweeps results, a stress of $10 \mathrm{~Pa}$ was within the linear viscoelastic region in all the samples. Thus, frequency sweeps were performed at $10 \mathrm{~Pa}$. All samples exhibited the viscoelastic properties usually observed for weak-gel systems; the elastic response predominated over the viscous one, and both dynamic moduli showed only a slight variation with oscillation frequency. For all samples, frequency dependencies of dynamic moduli became parallel. Differences in mechanical spectra between regular- and reduced-fat samples of the same brand increased when their comparative fat reduction increased, and the differences observed between each pair of samples were greater at $10^{\circ} \mathrm{C}$ than at $22^{\circ} \mathrm{C}$. These differences in viscoelastic behavior can be illustrated by the mechanical spectra obtained at 22 and $10^{\circ} \mathrm{C}$ for commercial spreadable cheeses of brands $\mathrm{A}$ and $\mathrm{D}$ (Figure 5). For comparative purposes, values of $\mathrm{G}^{\prime}, \mathrm{G}^{\prime \prime}, \tan \delta, \eta^{*}$ at $1 \mathrm{~Hz}\left(\eta^{*}{ }_{1 \mathrm{~Hz}}\right)$, and $\eta^{*}{ }_{8 \mathrm{~Hz}}$ were considered. To comparatively analyze the influence of temperature on each of these viscoelastic parameters of spreadable cheese samples, a 2-way ANOVA with the interaction was performed (Table 2). The results showed significant interactions between sample and temperature for the values of all viscoelastic parameters considered. This indicates the extent to which the temperature affecting the viscoelastic parameter values depended on sample composition. As a general trend and for each commercial brand, except for regular- and low-fat samples of brand $\mathrm{A}$, the regular-fat samples showed higher values for $\mathrm{G}^{\prime}$ and $\eta^{*}{ }_{1 \mathrm{~Hz}}$ than did the low-fat samples at the 2 temperatures (Table 3 ). When
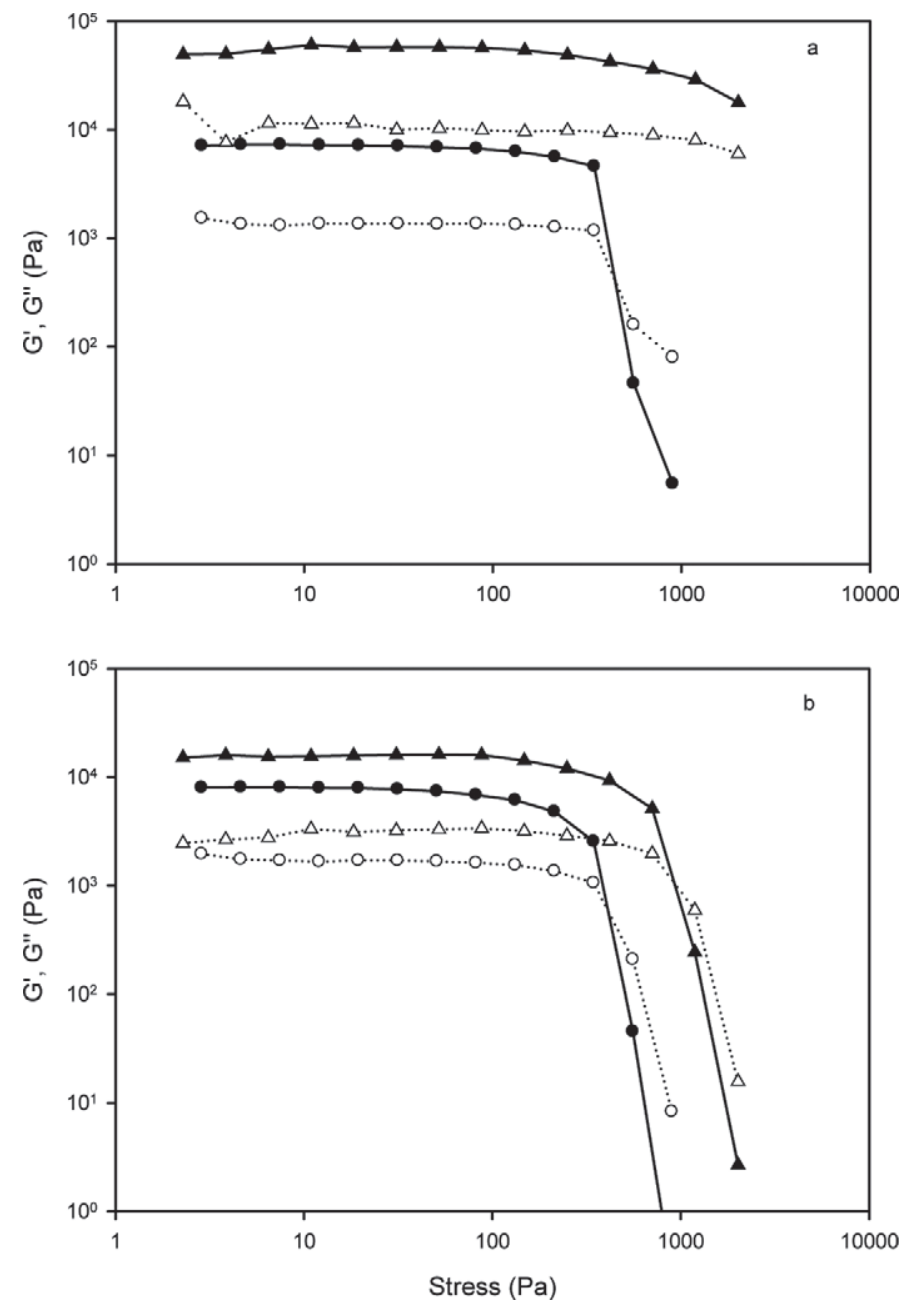

Figure 3. Stress sweeps of commercial spreadable cheeses of brand D: a) regular fat (19.8\% fat) and b) low fat (0.3\% fat) at different temperatures (circles, $22^{\circ} \mathrm{C}$; triangles, $\left.10^{\circ} \mathrm{C}\right)$. Storage modulus $\left(\mathrm{G}^{\prime}\right.$; filled symbols) and loss modulus ( $\mathrm{G}^{\prime \prime}$; empty symbols). 


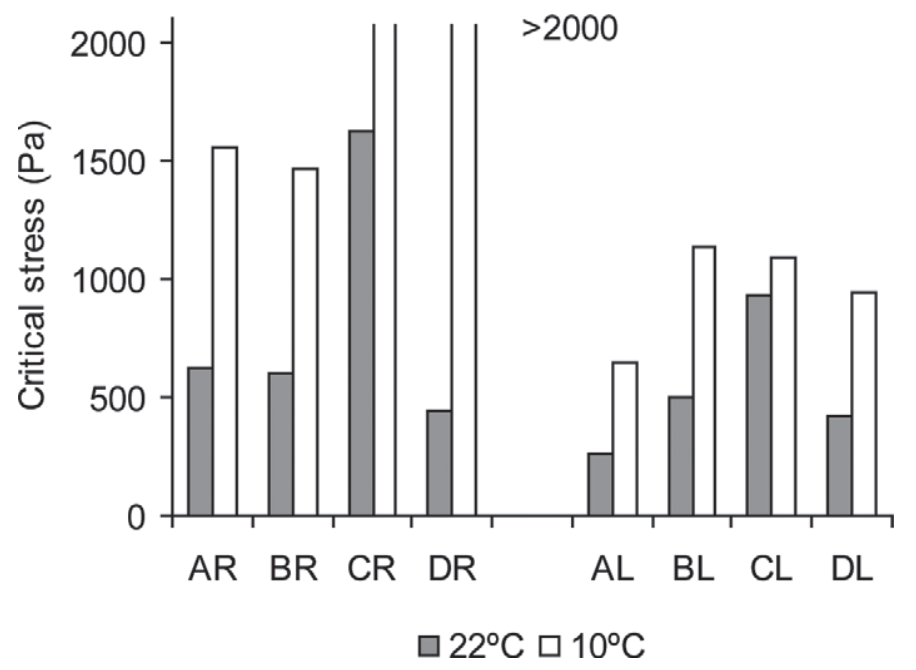

Figure 4. Critical stress value of commercial spreadable cheeses at room temperature $\left(22^{\circ} \mathrm{C}\right)$ and refrigeration temperature $\left(10^{\circ} \mathrm{C}\right) . \mathrm{A}$, $\mathrm{B}, \mathrm{C}, \mathrm{D}=$ different commercial brands; $\mathrm{R}=$ regular-fat samples; $\mathrm{L}=$ low-fat samples.

the temperature decreased, the $\mathrm{G}^{\prime}, \mathrm{G}^{\prime \prime}$, and $\eta^{*}$ values increased for both the regular- and low-fat samples to a different extent. For most of the regular-fat samples, the $\mathrm{G}^{\prime}$ and $\mathrm{G}^{\prime \prime}$ values increased significantly $(P \leq 0.05)$. Among the low-fat samples, the only significant $(P \leq$ $0.05)$ increase in the $\mathrm{G}^{\prime}$ value corresponded to the lowfat sample of brand A (13.0\% of fat). In any case, some significant differences detected in $\mathrm{G}^{\prime}, \mathrm{G}^{\prime \prime}$, and $\eta^{*}$ values at $10^{\circ} \mathrm{C}$ among the 8 samples were not detected when measurements were taken at $20^{\circ} \mathrm{C}$ (Table 3). A similar result was observed by Brighenti et al. (2008) between the effects of temperature on the viscoelasticity of commercial US cream cheeses with differing fat content. They observed that significant differences existed in $\mathrm{G}^{\prime}$ values at $8^{\circ} \mathrm{C}$ among cheeses with differing fat content, although at temperatures above $25^{\circ} \mathrm{C}$, no consistent differences were observed in the $\mathrm{G}^{\prime}$ values among the same cheeses. The $\tan \delta$, which is defined as the ratio of $G^{\prime \prime}$ to $G^{\prime}$, is a measurement of the viscous properties relative to the elastic properties of a viscoelastic material. The spreadable cheese samples analyzed presented a structure that could be characterized as viscoelastic gels because $\tan \delta$ values ranged from 0.17 to 0.24 at $10^{\circ} \mathrm{C}$ and from 0.18 to 0.28 at $22^{\circ} \mathrm{C}$ (Table 3 ). A significant interaction was also observed between sample composition and temperature measurement in the tan $\delta$ values (Table 2). For the regular-fat cheese samples, a decrease in temperature produced a slight decrease in $\tan \delta$ values, without any significant intersample differences apart from those of brand $\mathrm{C}$ samples. Regarding the low-fat samples, decreasing the temperature also produced a decrease in $\tan \delta$ values that was more pronounced in samples $\mathrm{C}$ and $\mathrm{D}$ with a lower fat content. As expected, intersample differences in the value of $\eta^{*}{ }_{8 \mathrm{~Hz}}$ attributable to fat content or to temperature were similar to those observed for $\eta^{*}$ values (Table 3 ). When temperature decreased, the value of $\eta^{*}{ }_{8 \mathrm{~Hz}}$ for both regular- and reduced-fat samples increased. When measurements were taken at $20^{\circ} \mathrm{C}$, no significant differences in the values of $\eta^{*}{ }_{8 \mathrm{~Hz}}$ between regular- and low-fat samples of each brand were detected. At $10^{\circ} \mathrm{C}$, significant differences in values for $\eta^{*}{ }_{8 \mathrm{~Hz}}$ were detected only for samples of brand C (Figure 6).

To study the joint variability of viscoelastic parameters, principal components analysis was applied to their mean values (Figure 7). The first component accounted
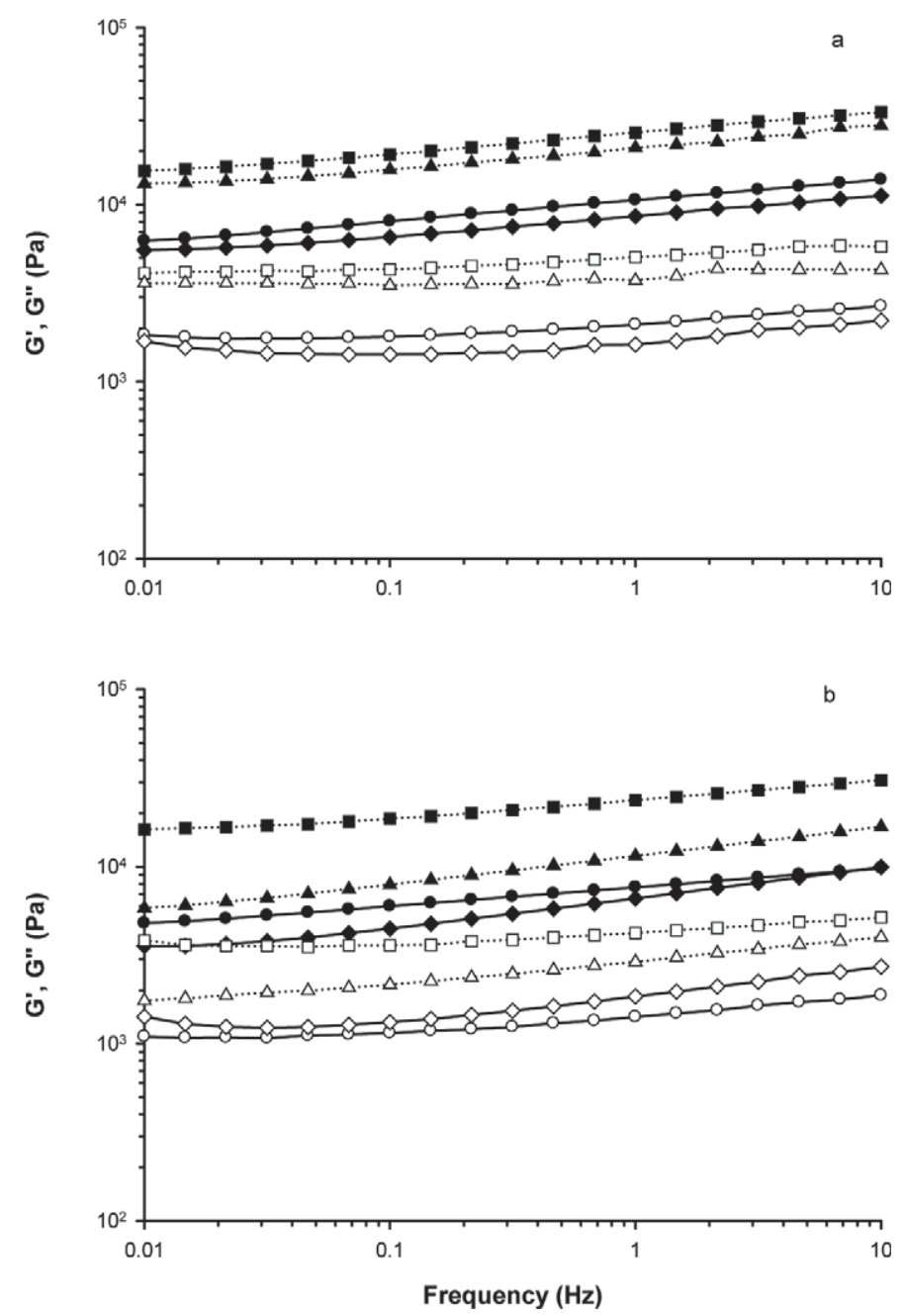

Figure 5. Mechanical spectra of spreadable cheeses of brands A (a) and D (b): regular fat (20 and 19.8\% fat, respectively; circles and squares) and low fat (13 and $0.3 \%$ fat, respectively; rhombuses and triangles) at different temperatures $\left(22^{\circ} \mathrm{C}\right.$, continuous line; $10^{\circ} \mathrm{C}$, dotted line). Storage modulus ( $\mathrm{G}^{\prime}$; filled symbols) and loss modulus ( $\mathrm{G}^{\prime \prime}$; empty symbols). 
Table 2. Two-way ANOVA with the interaction of viscoelastic parameter values of spreadable cheeses ${ }^{1}$

\begin{tabular}{|c|c|c|c|c|c|c|c|c|c|c|}
\hline $\begin{array}{l}\text { Source of } \\
\text { variation }\end{array}$ & \multicolumn{2}{|c|}{$\mathrm{G}^{\prime}(\mathrm{Pa})$} & \multicolumn{2}{|c|}{$\mathrm{G}^{\prime \prime}(\mathrm{Pa})$} & \multicolumn{2}{|c|}{$\eta^{*}{ }_{1 \mathrm{~Hz}}(\mathrm{~Pa} / \mathrm{s})$} & \multicolumn{2}{|c|}{$\tan \delta$} & \multicolumn{2}{|c|}{$\eta^{*}{ }_{8 \mathrm{~Hz}}(\mathrm{~Pa} / \mathrm{s})$} \\
\hline Sample & 5.217 & 0.003 & 6.128 & 0.001 & 5.270 & 0.003 & 50.590 & $<0.0001$ & 5.159 & 0.003 \\
\hline Interaction & 2.773 & 0.043 & 3.336 & 0.022 & 2.792 & 0.042 & 2.856 & 0.039 & 2.826 & 0.040 \\
\hline
\end{tabular}

${ }^{1}$ Storage modulus $\left(\mathrm{G}^{\prime}\right)$, loss modulus $\left(\mathrm{G}^{\prime \prime}\right)$, complex dynamic viscosity at $1 \mathrm{~Hz}\left(\eta^{*}{ }_{1 \mathrm{~Hz}}\right)$, complex dynamic viscosity at $8 \mathrm{~Hz}\left(\eta^{*} 8 \mathrm{~Hz}\right)$, and loss tangent $(\tan \delta)$.

for $85.28 \%$ of the total variability and clearly separated the samples, except the fat-free sample of brand D, according to the temperature measurement. Samples with differing fat content measured at $10^{\circ} \mathrm{C}$, were in the positive part of the first dimension and showed higher values for most of the viscoelastic parameters $\left(G^{\prime}, G^{\prime \prime}\right.$, $\left.\eta^{*}, \eta^{*}{ }_{8 \mathrm{~Hz}}\right)$ than those measured at $22^{\circ} \mathrm{C}$, which were in the negative part of the first dimension. The increase in viscoelastic parameter values when the temperature decreased from 22 to $10^{\circ} \mathrm{C}$ could suggest some substantial changes in the number of links between protein aggregates and in the state of the fat (Lucey et al., 2003). In spreadable cheeses, protein-protein interactions can increase when the temperature decreases, and the distribution of fat within the protein matrix can change because of partial milk fat crystallization. Gliguem et al. (2009) studied the thermal, rheological, and structural behaviors of high-fat spreadable processed cheese over a wide temperature range. They reported that above $14^{\circ} \mathrm{C}$, the cheese fat fraction remained in the liquid state, and below $14^{\circ} \mathrm{C}$, the fat matter in the processed cheese droplets consisted of a mixture of the liquid and solid

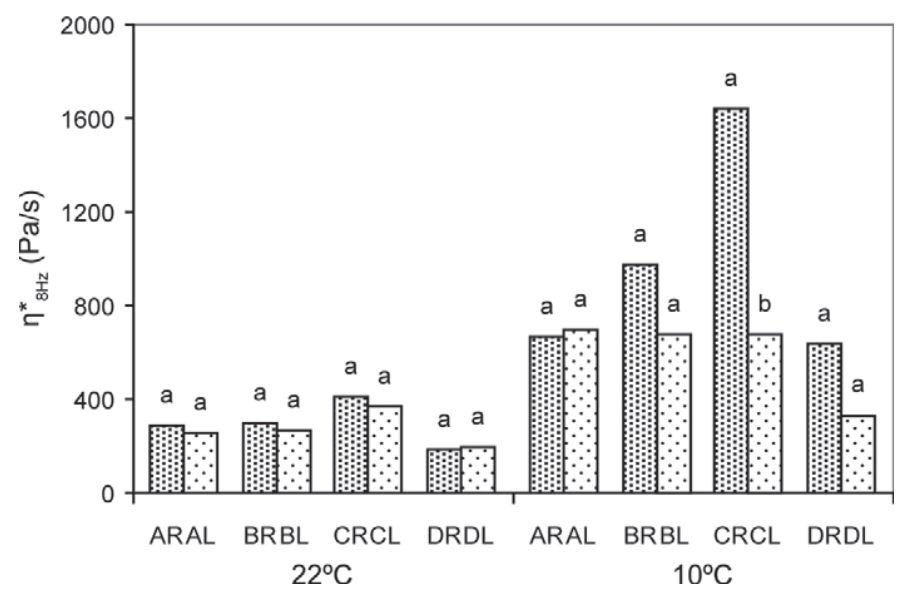

Figure 6. Difference in complex viscosity values at $8 \mathrm{~Hz}$ between regular-fat (R; gray bars) and low-fat (L; white bars with dots) samples of each commercial brand (A, B, C, D) at 2 temperatures, room temperature $\left(22^{\circ} \mathrm{C}\right)$ and refrigeration temperature $\left(10^{\circ} \mathrm{C}\right)$. Means with common letters $(\mathrm{a}, \mathrm{b})$ within each pair do not differ significantly $(P$ $\leq 0.05)$. A, B, C, D = samples of different commercial brands; $\mathrm{R}=$ regular-fat samples; $\mathrm{L}=$ low-fat samples. phases of different triacylglycerols. They also observed that between 13 and $3{ }^{\circ} \mathrm{C}$, viscoelastic modulus values increased faster because of the crystallization of some milk fat triacylglycerols embedded in the fat droplets. They concluded that this crystallization reinforced the proteins anchored onto the droplets and thus contributed to the increase in viscoelastic modulus values of the cheeses at the low temperature. These facts can explain the differences observed in the $G^{\prime}$ and $G^{\prime \prime}$ values in our work because of the temperature change and also the stronger effect of temperature variation on viscoelastic modulus values for cheeses with a regular-fat content. For fat-free samples, decreasing the temperature also increased $G^{\prime}$ and $G^{\prime \prime}$ values, although to a lesser extent. This effect cannot be explained by changes in the fat state, but it could be due to a decrease in the hydrophobic interactions and also to an increase in the strength of hydrogen bonds (Brighenti et al., 2008). The second component, which accounted for only a low percentage of variability (14.59\%), correlated well with tan $\delta$. Samples with a low-fat content (brands $\mathrm{C}$ and D) at both measurement temperatures $\left(10\right.$ and $\left.22^{\circ} \mathrm{C}\right)$, exhibited the highest $\tan \delta$ values, indicating that they had less structured matrices.

\section{Mechanical Characteristics}

The influence of temperature on mechanical parameter values obtained by the spreadability test was analyzed by applying 2-way ANOVA with the interaction (Table 4). No significant interaction was detected between sample and temperature on adhesiveness. A similar increase in the value of this trait was detected for all samples when the temperature decreased from 22 to $10^{\circ} \mathrm{C}$ (Table 5). Significant sample $\times$ temperature interactions for the values of firmness, spreadability, and stickiness indicate that the effect of temperature on these mechanical characteristics was not the same for all samples. In general, and as expected, samples measured at $10^{\circ} \mathrm{C}$ showed higher firmness and stickiness and more resistance to spreading than did samples measured at $22^{\circ} \mathrm{C}$, confirming the importance of fat state (liquid or crystal) on the mechanical properties of 
Table 3. Effect of room temperature $\left(22^{\circ} \mathrm{C}\right)$ and refrigeration temperature $\left(10^{\circ} \mathrm{C}\right)$ on viscoelastic parameters [storage modulus $\left(\mathrm{G}^{\prime}\right)$, loss modulus $\left(\mathrm{G}^{\prime \prime}\right)$, complex dynamic viscosity at $1 \mathrm{~Hz}\left(\eta^{*}{ }_{1 \mathrm{~Hz}}\right)$, and loss tangent $\left.(\tan \delta)\right]$ values of spreadable cheeses ${ }^{1}$

\begin{tabular}{|c|c|c|c|c|c|c|c|c|}
\hline \multirow[b]{2}{*}{ Sample $^{2}$} & \multicolumn{2}{|c|}{$\mathrm{G}^{\prime}\left(10^{-3} \mathrm{~Pa}\right)$} & \multicolumn{2}{|c|}{$\mathrm{G}^{\prime \prime}\left(10^{-3} \mathrm{~Pa}\right)$} & \multicolumn{2}{|c|}{$\tan \delta$} & \multicolumn{2}{|c|}{$\eta^{*}{ }_{1 \mathrm{~Hz}}(\mathrm{~Pa} / \mathrm{s})$} \\
\hline & $22^{\circ} \mathrm{C}$ & $10^{\circ} \mathrm{C}$ & $22^{\circ} \mathrm{C}$ & $10^{\circ} \mathrm{C}$ & $22^{\circ} \mathrm{C}$ & $10^{\circ} \mathrm{C}$ & $22^{\circ} \mathrm{C}$ & $10^{\circ} \mathrm{C}$ \\
\hline $\mathrm{AR}$ & $10.7^{\text {cde }}$ & $25.3^{\mathrm{bcd}}$ & $2.1^{\mathrm{d}}$ & $4.8^{\mathrm{bc}}$ & $0.20^{\mathrm{cd}}$ & $0.19^{\text {cde }}$ & $1,735^{\text {cdef }}$ & $4,101^{\mathrm{bcd}}$ \\
\hline $\mathrm{AL}$ & $10.0^{\mathrm{de}}$ & $26.4^{\mathrm{bc}}$ & $1.9^{\mathrm{d}}$ & $4.7^{\mathrm{bc}}$ & $0.19^{\text {cdef }}$ & $0.18^{\text {efg }}$ & $1,480^{\mathrm{ef}}$ & $4,261^{\mathrm{bc}}$ \\
\hline $\mathrm{BR}$ & $11.4^{\text {cde }}$ & $36.8^{\mathrm{b}}$ & $2.0^{\mathrm{d}}$ & $6.3^{\mathrm{b}}$ & $0.18^{\text {efg }}$ & $0.17^{\mathrm{fg}}$ & $1,850^{\text {cdef }}$ & $5,937^{\mathrm{b}}$ \\
\hline $\mathrm{BL}$ & $10.3^{\text {cde }}$ & $24.9^{\text {bcd }}$ & $1.9^{\mathrm{d}}$ & $4.6^{\mathrm{bc}}$ & $0.19^{\text {cdef }}$ & $0.18^{\text {def }}$ & $1,669^{\mathrm{def}}$ & $4,033^{\text {bcde }}$ \\
\hline $\mathrm{CR}$ & $15.5^{\text {cde }}$ & $62.3^{\mathrm{a}}$ & $2.9^{\mathrm{cd}}$ & $10.1^{\mathrm{a}}$ & $0.19^{\text {cdef }}$ & $0.17^{\mathrm{g}}$ & $2,504^{\text {cdef }}$ & $10,040^{\mathrm{a}}$ \\
\hline $\mathrm{DL}$ & $6.5^{\mathrm{e}}$ & $11.2^{\text {cde }}$ & $1.8^{\mathrm{d}}$ & $2.8^{\mathrm{cd}}$ & $0.28^{\mathrm{a}}$ & $0.24^{\mathrm{b}}$ & $1,067^{\mathrm{f}}$ & $1,829^{\text {cdef }}$ \\
\hline
\end{tabular}

${ }^{\mathrm{a}-\mathrm{g}}$ Means for each viscoelastic parameter at both temperatures with different superscripts differ $(P \leq 0.05)$.

${ }^{1}$ Average values $(\mathrm{n}=4)$.

${ }^{2} \mathrm{~A}, \mathrm{~B}, \mathrm{C}, \mathrm{D}=$ samples of different commercial brands; $\mathrm{R}=$ regular-fat samples; $\mathrm{L}=$ low-fat samples.

spreadable cheeses. Results obtained previously show the highly negative relationship between firmness and spreadability values (Brighenti et al., 2008), although here some differences in the relative variations of both characteristics were detected (Table 5). Differences can be explained by the fact that spreadability is a more dynamic property than firmness, and its value was influenced not only by the force required to obtain a given deformation but also by the effect of the work softening produced on samples during measurement.

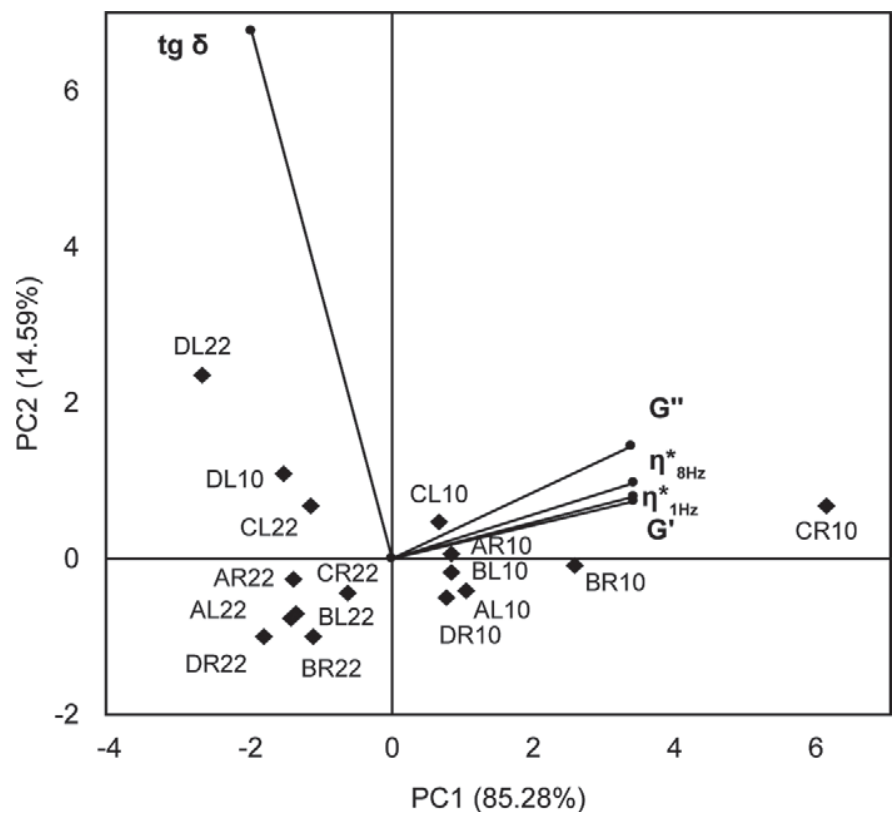

Figure 7. Principal components analysis bi-plot of the viscoelastic parameters of commercial spreadable cheeses at room temperature $\left(22^{\circ} \mathrm{C}\right)$ and refrigeration temperature $\left(10^{\circ} \mathrm{C}\right) . \mathrm{A}, \mathrm{B}, \mathrm{C}, \mathrm{D}=$ different commercial brands; $\mathrm{R}=$ regular-fat content; $\mathrm{L}=$ low-fat content. $\mathrm{G}^{\prime}$ $=$ storage modulus; $\mathrm{G}^{\prime \prime}=$ loss modulus; $\eta^{*}{ }_{1 \mathrm{~Hz}}=$ complex dynamic viscosity at $1 \mathrm{~Hz} ; \eta^{*}{ }_{8 \mathrm{~Hz}}=$ complex dynamic viscosity at $8 \mathrm{~Hz} ; \tan \delta$ $=$ loss tangent.
For each commercial brand, the regular-fat samples were found to have greater firmness and stickiness and less spreadability than the low-fat ones at the 2 temperatures, with the exception of brand A samples. Samples of the latter brand, with the lower fat reduction percentage and with a fat content difference of $7 \%$, showed no significant differences in firmness, stickiness, spreadability, or adhesiveness at either temperature measurement (Table 5). These results were in agreement with those obtained for $\mathrm{G}^{\prime}, \eta^{*}{ }_{1 \mathrm{~Hz}}$ (Table 3), and $\eta^{*}{ }_{8 \mathrm{~Hz}}$ (Figure 6) for these samples, and this would seem to confirm that changes in fat content below $12 \%$ would not have an effect on cream cheese texture (Wendin et al., 2000). In accordance with the results obtained previously for viscoelastic parameters, significant differences in mechanical parameters detected at $10^{\circ} \mathrm{C}$ between samples with differing fat content for each brand were not detected when measurements were taken at $22^{\circ} \mathrm{C}$, except for brand $\mathrm{D}$ samples. The latter samples showed significant differences in firmness and spreadability at both temperature measurements $\left(10\right.$ and $22^{\circ} \mathrm{C}$ ) and also on stickiness at $22^{\circ} \mathrm{C}$ (Table $5)$. The fat-free sample of brand D was significantly less firm and more spreadable than the corresponding regular-fat sample. Previous studies have commented on the different effects of temperature variation on viscoelastic characteristics of fat-free samples (as in brand D) compared with other samples. A similar effect on their mechanical properties was also detected. This probably reflects the influence of other changes in product formulation on the rheological and mechanical properties of commercial cream cheeses (Wendin et al., 2000; Mistry, 2001; Brighenti et al., 2008).

\section{Sensory Characteristics}

To know whether the ingestion temperature influences the sensory textural differences perceived between 
Table 4. Two-way ANOVA with the interaction of mechanical parameter values of spreadable cheeses, obtained with the spreadability test

\begin{tabular}{|c|c|c|c|c|c|c|c|c|}
\hline $\begin{array}{l}\text { Source of } \\
\text { variation }\end{array}$ & \multicolumn{2}{|c|}{ Firmness $(\mathrm{N})$} & \multicolumn{2}{|c|}{ Stickiness $(\mathrm{N})$} & \multicolumn{2}{|c|}{ Spreadability (N/s) } & \multicolumn{2}{|c|}{ Adhesiveness (N/s) } \\
\hline Sample & 13.054 & $<0.0001$ & 8.905 & 0.000 & 14.721 & $<0.0001$ & 5.884 & 0.002 \\
\hline Interaction & 7.449 & 0.0005 & 4.891 & 0.004 & 6.590 & 0.001 & 1.376 & 0.281 \\
\hline
\end{tabular}

regular- and low-fat samples of each commercial brand, differences in thickness, creaminess, and roughness were evaluated in 2 sessions by means of a paired comparisons test. In the first session, samples were compared at $22^{\circ} \mathrm{C}$ and in the second, at $10^{\circ} \mathrm{C}$.

Significant differences in thickness were detected between each pair of samples of brands A, B, and D when evaluated at $22^{\circ} \mathrm{C}$ and only between brand $\mathrm{C}$ samples when evaluated at $10^{\circ} \mathrm{C}$ (Figure 8a). Results obtained at $22^{\circ} \mathrm{C}$ could be considered surprising, whereas results obtained at $10^{\circ} \mathrm{C}$ coincided totally with those obtained from values of the instrumental index of oral thickness (Figure 6). To interpret differences, as well as similarities, between instrumental measurements and the sensory evaluation of thickness, one should jointly consider the effects of intersample variation in composition, the influence of product temperature on the fat state, and the role of oral processing on cream cheese characteristics. At the higher temperature measurement $\left(22^{\circ} \mathrm{C}\right)$, the regular-fat sample of brand A was perceived as thicker than its corresponding low-fat sample. A different trend was observed for samples of brands B, C, and D. For these brands, the low-fat samples were perceived as thicker. The higher protein content of the low-fat samples of brands B, C, and D compared with the regular-fat samples of brands B, C, and D (Table 1) could change the product structure, increasing the number of links between protein aggregates and slightly reinforc- ing the strength of the protein matrix. These structural changes seem to be insufficient to influence the values of $\eta^{*}{ }_{8 \mathrm{~Hz}}$ (Figure 6) or resistance to spreading (Table 5) of samples, although they can modify their behavior during oral processing. At this temperature, the sample fat content remains in the liquid state, and it could act as a lubricant; protein could also play a greater role in thickness perception. When measurements were taken at $10^{\circ} \mathrm{C}$, cheese fat was a mixture of the liquid and solid phases, and the solid phase reinforces the protein matrix. It can be speculated that, at this temperature, the effect of fat was more important to reinforcing the cheese structure than that exerted by the variation in protein content.

Differences in creaminess showed similar trends at both measurement temperatures (Figure 8b). The same result was recorded by Engelen et al. (2003), who compared the creaminess of high- and low-fat custards at the same 2 temperatures. No significant overall effect of product temperature on creaminess was detected. In our study, the most important difference in creaminess was perceived between samples of brand D, which had the greatest difference in fat content. The regular-fat sample was perceived as significantly creamier than the fat-free sample at both temperatures. Greater differences in roughness were also detected for brand D samples (Figure 8c). The fat-free sample was perceived as significantly rougher than the regular-fat sample at

Table 5. Effects of room temperature $\left(22^{\circ} \mathrm{C}\right)$ and refrigeration temperature $\left(10^{\circ} \mathrm{C}\right)$ on the mechanical parameter values of spreadable cheeses, obtained with the spreadability test ${ }^{1}$

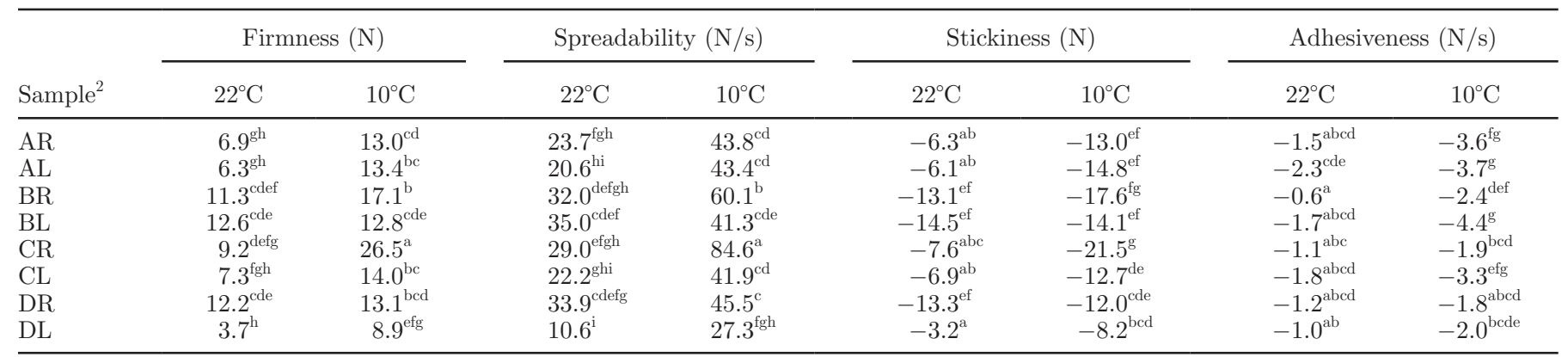

${ }^{\mathrm{a}-\mathrm{i}}$ Means for each viscoelastic parameter at both temperatures with different superscripts differ $(P \leq 0.05)$.

${ }^{1}$ Average values $(\mathrm{n}=4)$.

${ }^{2} \mathrm{~A}, \mathrm{~B}, \mathrm{C}, \mathrm{D}=$ samples of different commercial brands; $\mathrm{R}=$ regular-fat samples; $\mathrm{L}=$ low-fat samples 
the 2 temperatures. These results were in accordance with the well-known opposite relationship between perceptions of roughness and creaminess.
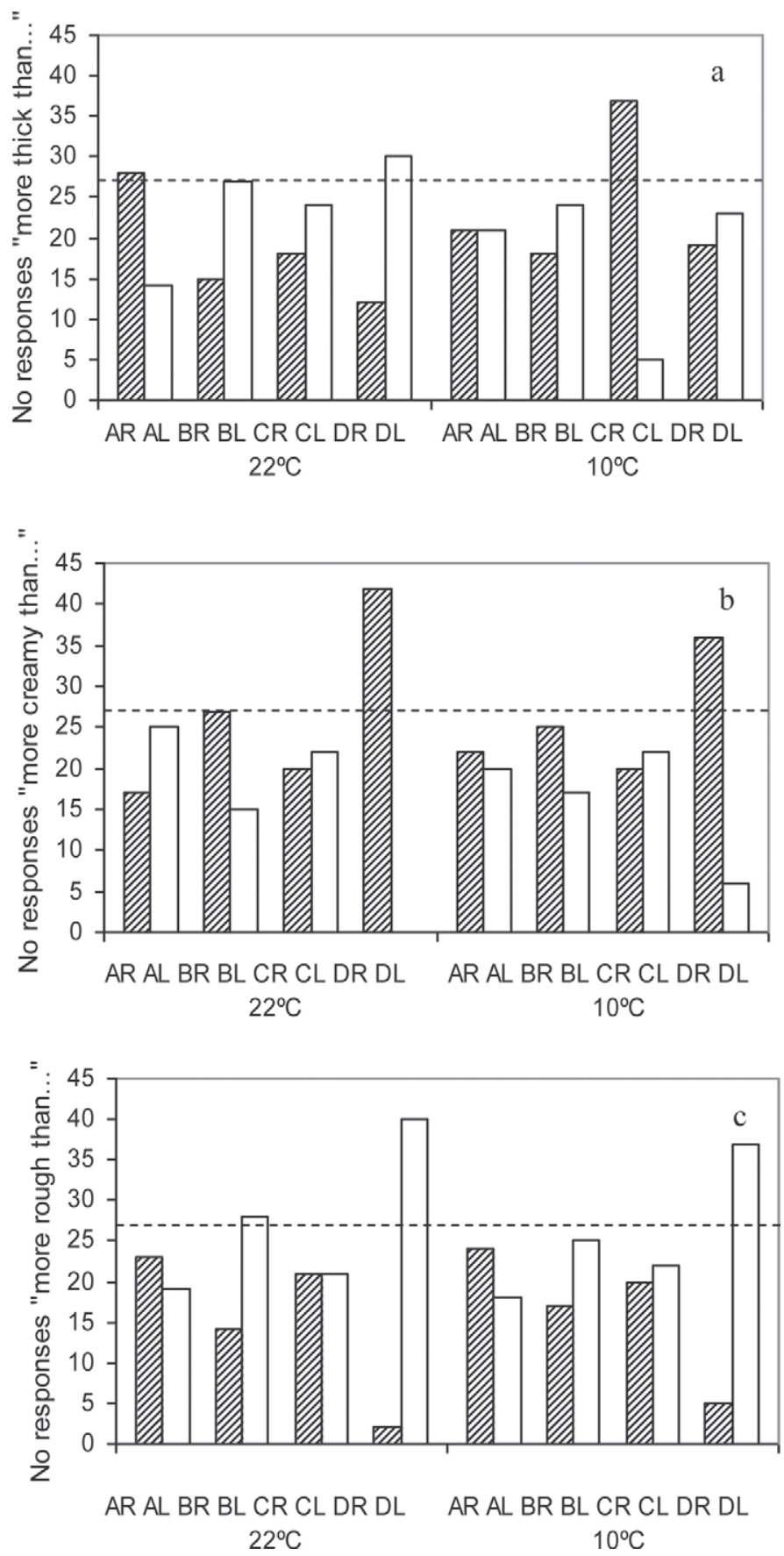

Figure 8. Sensory evaluation of differences between regular-fat (R; diagonally striped bars) and low-fat (L; open bars) samples of each commercial brand (A, B, C, D) at 2 temperatures, room temperature $\left(22^{\circ} \mathrm{C}\right)$ and refrigeration temperature $\left(10^{\circ} \mathrm{C}\right)$ : a) thickness, b) creaminess, and c) roughness. The dotted line indicates the minimum value of the response for which the difference is significant $(P=0.05)$.

\section{CONCLUSIONS}

The viscoelasticity and mechanical characteristics of the commercial spreadable cheeses analyzed were affected by the change in temperature from 22 to $10^{\circ} \mathrm{C}$. At the lower temperature, samples showed a more solidlike behavior with a higher critical stress, higher $\mathrm{G}^{\prime}$, and higher $\eta^{*}$ values and with lower $\tan \delta$ values. A similar trend was observed for mechanical characteristics, with samples at $10^{\circ} \mathrm{C}$ being firmer, stickier, and less spreadable. The observed temperature-related variations were higher for regular-fat samples than for low-fat ones, confirming the important role of fat content on both the viscoelasticity and mechanical characteristics of cheeses. Differences in viscoelasticity and mechanical properties between each pair of samples were more important at $10^{\circ} \mathrm{C}$ than at $22^{\circ} \mathrm{C}$. This was due to the influence not only of fat content but also of fat state. The product temperature at the moment of ingestion did not modify the sensory differences in creaminess and roughness detected between each sample pair differing in fat content of the same brand, but it did modify the differences detected in thickness. More information is needed to reveal the extent to which the fat-to-protein ratio influences the perceived thickness of cream cheeses and to explain the sensory results obtained at different temperatures. The information reported here confirms the convenience of selecting the adequate temperature or temperatures to measure the physical and sensory properties of cream cheeses mainly for product formulation or quality control purposes.

\section{ACKNOWLEDGMENTS}

Fondo Social Europeo is acknowledged for financing the contract of S. Bayarri in the program I3P from Consejo Superior de Investigaciones Científicas (CSIC, Madrid, Spain). The authors also thank Jihan M. A. Ayesh (University of Valencia, Valencia, Spain) for collaboration in the experimental work.

\section{REFERENCES}

Banks, J. 2007. Producing low-fat cheese. Pages 520-536 in Improving the Flavour of Cheese. B. C. Weimer, ed. Woodhead Publishing Limited/CRC Press, Cambridge, UK.

Bayarri, S., L. González-Tomás, and E. Costell. 2009. Viscoelastic properties of aqueous and milk systems with carboxymethyl cellulose. Food Hydrocoll. 23:441-450.

Bayarri, S., L. González-Tomás, I. Hernando, M. A. Lluch, and E. Costell. 2011. Texture perceived on inulin-enriched low-fat semisolid dairy desserts. Rheological and structural basis. J. Texture Stud. 42:174-184.

Bayarri, S., M. Martí, I. Carbonell, and E. Costell. 2012. Sensory impact on consumer response to spreadable cheeses with different fat content. J. Sens. Stud. 27:1-11.

Breidinger, S. L., and J. F. Steffe. 2001. Texture map of cream cheese. J. Food Sci. 66:453-456. 
Brighenti, M., S. Govindasamy-Lucey, K. Lim, K. Nelson, and J. A. Lucey. 2008. Characterization of the rheological, textural, and sensory properties of samples of commercial US cream cheese with different fat contents. J. Dairy Sci. 91:4501-4517.

Canet, W., M. D. Alvarez, C. Fernández, and M. E. Tortosa. 2005. The effect of sample temperature on instrumental and sensory properties of mashed potato products. Int. J. Food Sci. Technol. 40:481-493.

Clark, A. H., and S. B. Ross-Murphy. 1987. Structural and mechanical properties of biopolymer gels. Adv. Polym. Sci. 83:57-192.

Daubert, C. R., J. A. Tkachuk, and V. D. Truong. 1998. Quantitative measurement of food spreadability using the vane method. J. Texture Stud. 29:427-435.

de Wijk, R. A., A. M. Janssen, and J. F. Prinz. 2011. Oral movements and the perception of semisolid foods. Physiol. Behav. 104:423428.

Dimitreli, G., and A. S. Thomareis. 2008. Effect of chemical composition on the linear viscoelastic properties of spreadable-type processed cheese. J. Food Eng. 84:368-374.

Engelen, L., R. A. de Wijk, J. F. Prinz, A. M. Janssen, H. Weenen, and F. Bosman. 2003. The effect of oral and product temperature on the perception of flavour and texture attributes of semisolids. Appetite 41:273-281.

Foegeding, E. A., and M. A. Drake. 2007. Sensory and mechanical properties of cheese texture. J. Dairy Sci. 90:1611-1624.

Glibowski, P., P. Zarzycki, and M. Krzepkowska. 2008. The rheological and instrumental textural properties of selected table fats. Int. J. Food Prop. 11:678-686.

Gliguem, H., D. Ghorbel, C. Lopez, C. Michon, M. Ollivon, and P. Lesieur. 2009. Crystallization and polymorphism of triacylglycerols contribute to the rheological properties of processed cheese. J. Agric. Food Chem. 57:3195-3203.

ISO (International Organization for Standardization). 1993. Sensory analysis. General Guidance for the selection, training and monitoring of assessors. Part 1: Selected assessors. Standard no. 8586-1. ISO, Geneva, Switzerland.

ISO (International Organization for Standardization). 2005. Sensory analysis. Methodology. Paired comparison test. Standard no. 5495:2005. ISO, Geneva, Switzerland.

ISO (International Organization for Standardization). 2007. General guidance for the design of test rooms. Standard no. 8589. ISO, Geneva, Switzerland.
Kulkurnain, M., M.-H. Goh, A. A. Karim, and M.-T. Liong. 2008. Development of a soy-based cream cheese. J. Texture Stud. 39:635654 .

Lee, S. K., S. Anema, and H. Klostermeyer. 2004. The influence of moisture content on the rheological properties of processed cheese spreads. Int. J. Food Sci. Technol. 39:763-771.

Liu, H., X. M. Xu, and S. D. Guo. 2008. Comparison of full-fat and low-fat cheese analogues with or without pectin gel through microstructure, texture, rheology, thermal and sensory analysis. Int. J. Food Sci. Technol. 43:1581-1592.

Lucey, J. A., M. E. Jonhnson, and D. S. Horne. 2003. Perspectives on the basis of the rheology and texture properties of cheese. J. Dairy Sci. 86:2725-2743.

Mistry, V. V. 2001. Low fat cheese technology. Int. Dairy J. 51:413422.

Muir, D. D., S. A. R. Williams, A. Y. Tamine, and M. E. Shenana 1997. Comparison of the sensory profiles of regular and reduced-fat commercial processed cheese spreads. Int. J. Food Sci. Technol. $32: 279-287$.

Piska, I., and J. Štětina. 2004. Influence of cheese ripening and rate of cooling of the processed cheese mixture on rheological properties of processed cheese. J. Food Eng. 61:551-555.

Rao, M. A. 2007. Rheology of Fluid and Semisolid Foods. 2nd ed. Springer, New York, NY.

Swenson, B. J., W. L. Wendorff, and R. C. Linsay. 2000. Effects of ingredients on the functionality of fat-free process cheese spreads. Food Chem. Toxicol. 65:822-825.

Trivedi, D., R. J. Bennet, Y. Hemar, D. C. W. Reid, S. K. Lee, and D. Illingworth. 2008. Effect of different starches on rheological and microstructural properties of (I) model processed cheese. Int. J. Food Sci. Technol. 43:2191-2196.

van Vliet, T., G. A. van Aken, H. H. J. de Jongh, and R. J. Hammer 2009. Colloidal aspects of texture perception. Adv. Colloid Interface Sci. 150:27-40.

Weiserovà, E., L. Doudová, L. Galiová, L. Žák, J. Michálek, R. Janiš, and F. Buňka. 2011. The effect of combinations of sodium phosphates in binary mixtures on selected texture parameters of processed cheese spreads. Int. Dairy J. 21:979-986.

Wendin, K., M. Langton, L. Caous, and G. Hall. 2000. Dynamic analyses of sensory and microstructural properties of cream cheese. Food Chem. 71:363-378. 